\title{
Clinical, Bacteriological and Radiological study of severe pneumonia in age group of 2 months to 5 years
}

\author{
Mehta K. ${ }^{1}$, Shah V. ${ }^{2}$, Patel A. ${ }^{3}$, Kalsariya D. ${ }^{4}$ \\ ${ }^{1}$ Dr. Kirti Mehta, Associate Professor, ${ }^{2}$ Dr. Vijay Shah, Professor \& Head, ${ }^{3}$ Dr. Ankur Patel, Assistant Professor, \\ ${ }^{4}$ Dr. Dinesh Kalsariya, Ex- resident, all authors are affiliated with Pediatric Department, Government Medical College, \\ Surat, Gujrat, India.
}

Corresponding Author: Dr. Ankur Patel, Assistant Professor, Pediatric Department, Government Medical College, Surat, Gujrat, India. E-mail-dr.ankur.83@gmail.com

\begin{abstract}
Background: Acute respiratory infections (ARI) are one of the commonest causes of death in children in developing countries. The future health of children depends on preventing, diagnosing, treating and limiting Acute Lower Respiratory Tract Infection. The use of these clinical signs in the early detection and treatment of children with pneumonia by primary health care workers forms the basis for the case management strategy formulated by the World Health Organization (WHO) to control mortality and morbidity. Objectives: to study clinical, bacteriological and radiological features of severe pneumonia and to correlate clinical findings with radiological and bacteriological findings. Materials and Method: A prospective observational study among children between 2 months to 5 years of age. A detailed analysis of symptoms and signs such as fever, cough, rapid breathing, refusal of feeds, wheezing, respiratory rate, presence of fever and other signs of cyanosis, etc were noted. Investigations like Hemoglobin, Total WBC count, Differential WBC count, ESR, blood culture Chest X-ray and if require CT scan were done in all patients. Significance for the statistical tests was predetermined at a probability value of 0.05 or less. $(p<0.05)$ Results: over a period of one and half year total 150 cases were included in the study, nearly all patients were presented with cough, tachypnea, fever, chest retractions and other signs. Positive radiological finding were seen in $80.66 \%$ of cases. Among bacterial pneumonia, defined radiologicaly; $63.15 \%$ had elevated WBC counts; $88.42 \%$ had neutrophilia, $67.27 \%$ had elevated ESR. Case fatality rate was 6.3\% (9 cases). Conclusion: clinical diagnosis by WHO ARI criteria are very sensitive and still can be applied to hospitalized children. Chest X-ray is valuable aid in the diagnosis of pneumonia in children
\end{abstract}

Keywords: Childhood pneumonia, Radiological evaluation, Laboratory investigations, Blood culture

\section{Introduction}

Infections of respiratory tract are perhaps the most common human aliment. While they are a source of discomfort, disability and loss of time for most adults, they are a substantial cause of morbidity and mortality in young children [1].Acute respiratory infections (ARI) are one of the commonest causes of death in children in developing countries. It is responsible for an estimated 4 million deaths worldwide. Almost all ARI deaths in young children are due to acute lower respiratory tract infections (ALRTI), mostly pneumonia [2].

Modernization, industrialization and urbanization are now posed with the problem of increase in ARI morbidity and mortality. It is clear that future health of

Manuscript received: $10^{\text {th }}$ September 2018

Reviewed: $20^{\text {th }}$ September 2018

Author Corrected: $26^{\text {th }}$ September 2018

Accepted for Publication: $30^{\text {th }}$ September 2018 children depends on preventing, diagnosing, treating and limiting ALRTI. The utility of simple clinical signs like rapid breathing and chest in drawing to diagnose pneumonia in infants and young children has been well established.

The use of these clinical signs in the early detection and treatment of children with pneumonia by primary health care workers forms the basis for the case management strategy formulated by the World Health Organization (WHO) to control mortality and morbidity [3].

The empiric antibiotic therapy for pneumonia is the commonly accepted practice world wide as the etiology of pneumonia in children is difficult to establish. Clinical and radiological criteria do not accurately reflect the etiology of childhood pneumonia [4]. 


\section{Case Report}

ARI can be preventable. However socio environmental factors are acting as major obstacles in preventions of ARI. The epidemiological information regarding risk factors and management is scanty. A large gap exists in our knowledge about these factors, which need to be fulfilled by systemic studies.

The present study is designed to study clinical, bacteriological and radiological features of severe pneumonia and to correlate clinical findings with radiological and bacteriological findings.

\section{Materials \& Methodology}

Type of study:It was a prospective observational study.

Place of study: It wasconducted at pediatric department, Government medical college and new civil hospital, Surat. Institutional Human Research Ethics committee permission was taken before starting the study.

Inclusion criteria: Children between 2 months to 5 years with clinical features of severe pneumonia as per WHO guideline were included in the study.

Exclusion criteria: Children with congenital anomalies of heart and lungs, anatomical defects like cleft lip and claft palate, immunocompromised states and infants less than 2 months of age were excluded from the study.

Methods: Patients fulfilling the inclusion and exclusion criteria were included in the study only after taking inform written consent from legal guardian of the patients.

A detailed history of relevant symptoms such as fever, cough, rapid breathing, refusal of feeds, wheezing etc were noted. Based on WHO ARI criteria [5] children were considered tachypnoeic if respiratory rate:

$\mathrm{RR} \geq 60$ in $<2$ months

$R R \geq 50$ in 2 months -1 year

$R R \geq 40$ in 1 years to 5 years

A detailed examination of each child including anthropometry was carried out. Emphasis was laid on assessing general condition of child, respiratory rate, presence of fever and other signs of cyanosis, and pallor. Detailed systemic examination of respiratory, cardiovascular, and central nervous system were done. Any associated illness like septicemia, meningitis, and congestive cardiac failure if any was noted.

Investigations like Hemoglobin, Total WBC count, Differential WBC count, ESR, Chest X-ray and blood culture were done in all patients. Investigations were repeated according to need during treatment to see the progress of illness.

Statistical analysis: It was done using Microsoft Excel. Chi Squre test was used to determine significant differences between two groups. Odds ratio was determine whenever required. Significance for the statistical tests was predetermined at a probability value of 0.05 or less. $(p<0.05)$

\section{Results}

Over a period of one and half year total 150 patients with severe pneumonia were included in the study. Age and gender wise distribution of all [Table 1] shows more than half (53.33\%) were less than one years of age. And 59.33\% were male out of all 150 cases. The male: female ratio was found to be 1.46 .

Table-1: age and gender wise distribution of all cases.

\begin{tabular}{|c|c|c|c|}
\hline Age group (months) & Male (\%) & Female (\%) & Total (\%) \\
\hline $2-6$ & $36(40)$ & $21(34)$ & $57(38)$ \\
\hline $7-12$ & $16(18)$ & $07(12)$ & $23(15)$ \\
\hline $13-60$ & $37(42)$ & $33(54)$ & $70(47)$ \\
\hline Total & $\mathbf{8 9}(\mathbf{5 9 \%})$ & $\mathbf{6 1}(\mathbf{4 1})$ & $\mathbf{1 5 0}$ \\
\hline
\end{tabular}

The clinical presentation shows that common presenting symptoms were cough (100\%), tachypnea (100\%) and fever (99.33\%) which was seen in almost all cases. Other symptoms were refusal to feed, Wheezing, convulsion and cyanosis. Commonest sign was chest retraction (100\%) which was seen in all patients. Other signs were crepitations $(74.67 \%)$, ronchi $(51.33 \%)$ and other breath sounds $(25.33 \%)$. The mean duration of cough $(6.5 \pm 4.40)$ with ranges from $2-28$ days, fever $(5.67 \pm 4.26)$ with range of $1-20$ days, and tachypnea $(2.38 \pm 1.40)$ with range of $1-10$ days during hospital days. [Table $2 \& 3$ ] 


\section{Case Report}

Table-2: Presenting symptoms and signs in the all cases.

\begin{tabular}{|c|c|c|}
\hline Symptoms \& Signs & Numbers & Percentages \\
\hline Cough & 150 & 100 \\
\hline Fast breathing & 150 & 100 \\
\hline Chest retractions & 150 & 100 \\
\hline Fever & 149 & 99.3 \\
\hline Crepitations & 112 & 74.67 \\
\hline Ronchi & 77 & 51.33 \\
\hline Abnormal breath sounds & 38 & 25.33 \\
\hline Refusal of feeds & 29 & 19.3 \\
\hline Wheeze & 22 & 14.7 \\
\hline Convulsions & 07 & 4.6 \\
\hline Cyanosis & 05 & 3.3 \\
\hline
\end{tabular}

Table-3: mean duration and range of symptoms/signs.

\begin{tabular}{|c|c|c|c|}
\hline Symptoms/signs & Numbers & Duration in hospital (days ) & Range (days) \\
\hline Cough & 150 & $6.5 \pm 4.40$ & $2-28$ \\
\hline Fever & 149 & $5.67 \pm 4.26$ & $1-20$ \\
\hline Tachypnea & 150 & $2.38 \pm 1.40$ & $1-10$ \\
\hline Chest retraction & 150 & $2.12 \pm 1.14$ & $1-10$ \\
\hline $\begin{array}{c}\text { Added sounds } \\
\text { (crepitation/ronchi) }\end{array}$ & 113 & $4.78 \pm 1.42$ & $0-14$ \\
\hline
\end{tabular}

As seen in table 4,70 out of 80 children (87.5\%) below age 1 year had respiratory rate $>60 /$ min. And 69 out of 70 between age 1-5 years (98.57\%) had respiratory rate $>60 / \mathrm{min}$. So, division of all cases according to severity of pneumonia as per WHO ARI program shows that (125/150) i.e83.33\% were had sever pneumonia and 25/150 i.e.16.67\% had very severe pneumonia. Associated illness shows that 10 patients had diarrhea, 5 had septicemia, 3 had meningitis and 2 had congestive cardiac failure.

Table-4: Respiratory rate at the time of admission.

\begin{tabular}{|c|c|c|c|}
\hline $\mathbf{2}-\mathbf{1 2}$ months & $\mathbf{> 8 0} / \mathbf{m i n}$ & $\mathbf{6 0}-\mathbf{8 0} / \mathbf{m i n}$ & $<\mathbf{6 0} / \mathbf{m i n}$ \\
\hline No. of child & 01 & 69 & 10 \\
\hline $13-60$ months & $>/ \mathrm{min}$ & $50-60 / \mathrm{min}$ & $40-50 / \mathrm{min}$ \\
\hline No of child & 46 & 23 & 01 \\
\hline
\end{tabular}

Final clinical diagnosis shows that majority of the case were diagnosed as bronchopneumonia (66.67\%). Other diagnoses were lobar pneumonia (18.73\%), pneumonia with complications $(9.3 \%)$ and post measles bronchopneumonia (5.3\%).

The complications were empyema (7), pleural effusion (3), collapse (2) and pneumothorax (2).

As seen in figure 1, positive radiological finding were seen in $80.66 \%$ of cases. Among positive cases $78 \%$ were bacterial pneumonia, $14 \%$ were viral pneumonia, and $8 \%$ were non typable.

Among bacterial pneumonia consolidation was seen in $77 \%$ and alveolar infiltration in $23 \%$. Chest X-ray was normal in 29 cases. 


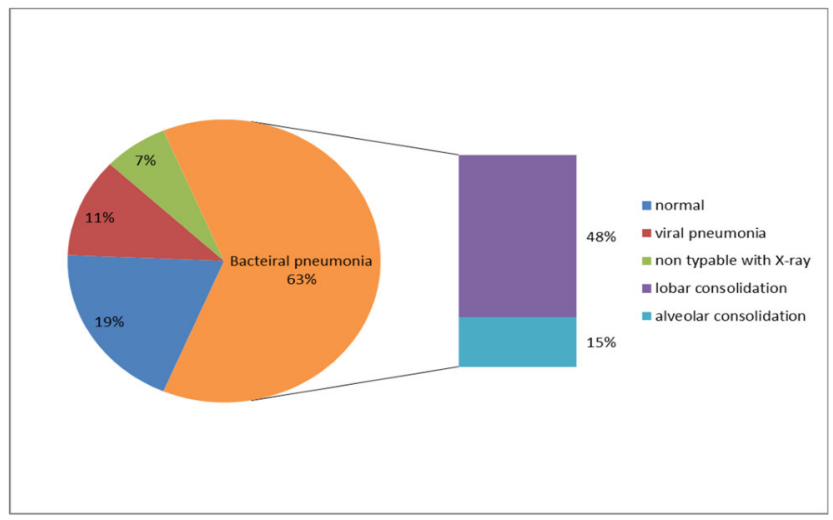

Figure-1: Radiological findings in all cases

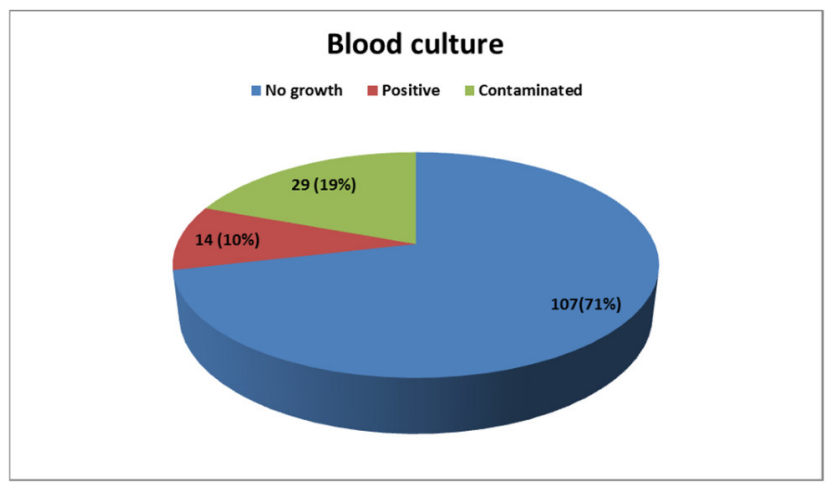

Figure-2: Blood culture of all cases

Blood culture was sent for all cases. They were positive only in 14 cases. While 107 cases shows no growth and 29 cultures were found contaminated. Among positive cultures S. pneumonia was the commonest isolate ( 5 cases) followed by S. aureus (5 cases) and Klebsiella (4 cases)[figure 2].

Table-5: clinical and radiological finding comparison of all cases.

\begin{tabular}{|c|c|c|c|}
\hline \multirow{2}{*}{ Clinical data } & \multirow{2}{*}{ No. } & \multicolumn{2}{|c|}{ Radiological findings } \\
\cline { 3 - 4 } & & Positive findings (\%) & Normal (\%) \\
\hline Tachypnea & 150 & $121(80.67)$ & $29(19.33)$ \\
\hline Chest retractions & 150 & $121(80.67)$ & $9(23.1)$ \\
\hline Crepitations only & 37 & $28(76.9)$ & $8(10.7)$ \\
\hline Crepitations + ronchi & 75 & $67(89.3)$ & $1(50)$ \\
\hline Ronchi only & O2 & $1(50)$ & $0(0)$ \\
\hline Abnormal breath sound & 22 & $22(100)$ & $(0)$ \\
\hline
\end{tabular}

Table-6: laboratory findings in comparison with radiological findings of all cases.

\begin{tabular}{|c|c|c|c|c|c|c|}
\hline Findings & $\begin{array}{c}\text { Total } \\
\mathbf{( 1 5 0 )}\end{array}$ & $\begin{array}{c}\text { Bacterial } \\
\mathbf{( 9 4 )}\end{array}$ & $\begin{array}{c}\text { Viral } \\
\mathbf{( 1 7 )}\end{array}$ & $\begin{array}{c}\text { Sensitivity } \\
\mathbf{( \% )}\end{array}$ & $\begin{array}{c}\text { Specificity } \\
\mathbf{( \% )}\end{array}$ & $\begin{array}{c}\text { Positive predictive value } \\
(\mathbf{\%})\end{array}$ \\
\hline WBC >1500/cumm & 150 & 60 & 11 & 63.16 & 61.82 & 74.07 \\
\hline DC neutrophilia & 150 & 84 & 08 & 88.42 & 58.18 & 78.50 \\
\hline ESR $>20 \mathrm{~mm} / \mathrm{hr}$ & 150 & 93 & 13 & 97.89 & 67.27 & 83.78 \\
\hline
\end{tabular}

Comparison of clinical findings with radiological findings are seen in table 5. While comparison of laboratory finding with radiological findings were shown in table 6 . In present study among bacterial pneumonia, defined radiologicaly; $63.15 \%$ had elevated WBC counts; $88.42 \%$ had neutrophilia, $67.27 \%$ had elevated ESR. There was no correlation of laboratory findings with bacterial and viral pneumonias defined radiologically. 
Case Report

Case fatality rate was $6.3 \%$ (9 cases) out of that $55.5 \%$ ( 5 cases) of death occurred within 24 hours of presentation to the hospital. Septicemia with shock was seen in $4(44.4 \%)$ cases and meningitis in $3(33.3 \%)$ cases. All cases belong to very severe pneumonia as per WHO ARI program.

\section{Discussion}

Pneumonia continues to pose a threat to health of children in developing and even developed countries despite improvement in socioeconomic status, immunization and early diagnosis and treatment. Universality, vulnerability and frequency of occurrence of acute lower respiratory tract infection (ALRTI) are well recognized all over the world.

The present study is conducted between the age group of 2 months to 5 years. And the majority of the cases $(53 \%)$ were below one year of age, which are comparable to other studies like Reddaiah VP et al (63.2\%) [6] and Sehgal V at al (52.2\%) [7]. Age is important predictor of morbidity and mortality in pediatric pneumonias. Also pneumonia is major cause for mortality in infant age group. Gender wise distribution shows $59.33 \%$ cases were male with $\mathrm{M}: \mathrm{F}$ ratio was 1.45 . This was in very much near to other studies like Sehgal V et al $(58.25 \%)$ and Drummond $\mathrm{P}$ et al $(58 \%)[7,8]$.

The WHO protocol puts forward two signs, cough and difficulty in breathing, as the "entry criteria" or basis for examination a child below five years of age for possible pneumonia. In this study $100 \%$ of cases presented with these both symptoms. Study by Kumar $\mathrm{N}$ et al [9] and Kabra SK et al [10] also shows similar findings with all cases with same presenting symptoms. While fever as present in almost all cases (99.3\%) in present study, it was less common in Kabra SK et al $(82 \%)$ and Kumar N et al $(88 \%)$. [9,10]. Refusal to feed was less common in present study as compare to that two study. Tachypnea is sensitive and specific indicator for grading of severity of pneumonia. Also traditional methods like auscultatory signs are still utilized for diagnosis of pneumonia in child with cough. In present study $100 \%$ cases had tachypnea and chest retractions. Crepitation (74.67\%), ronchi $(51.33 \%)$ and other abnormal sounds $(14.6 \%)$ were also commonly seen in present study. The findings are very much similar to other studies like Reddaiah VP et al [6] and Gupta D et al [11].

Associate illness like diarrhea (10 cases), congestive cardiac failure (1 case) and septicemia (2 cases) was seen in present study. This was in comparison to other study by Sehgal $\mathrm{V}$ et al [7]. In present study bronchopneumonia was the most common diagnosis made at admission $(60.6 \%)$. Other diagnosis were lobar pneumonia in $18.6 \%$, pneumonia with complications in $9.3 \%$ and post measles bronchopneumonia in $5.3 \%$ of cases. The complications of pneumonia were empyema, pleural effusion, collapse and pneumothorax. The study conducted by Reddaiah VP et al, shows bronchopneumonia (64\%), lobar pneumonia $(6.4 \%)$ and post measles bronchopneumonia (4\%)[6].

Although clinical symptoms and signs are helpful indicators in the presence of disease as well as etiology, radiographic investigation is often used to confirm a clinical diagnosis and to help sort out whether or not antibiotics or more extensive work up is necessary. In present study chest x-ray showed radiological changes consistent with pneumonia in $80.6 \%$ of cases. Evidence of bacterial infection was found in $78 \%$, viral in $14 \%$ and non-typable in $8 \%$ cases. Virkki R et al [12] found that radiological changes were seen in $85 \%$, with evidence of bacterial infection in $64 \%$ and viral in $36 \%$ of cases. This shows high incidence of bacterial infection in the country like ours because of lake of sanitary conditions and lake of hygiene. Also there may be variation in inter observer agreement on the radiographic features used for interpreting the radiogram. In follow up radiographs after treatments, $80 \%$ showed complete resolution and 20\% showed partial resolution. Study by Heaton P et al [13], showed $90.2 \%$ resolution of chest radiograph after treatment. They also concluded that for uncomplicated pneumonia follow up chest radiography id not indicated if symptoms and signs are absent.

In present study, comparison of clinical data with the radiological findings showed very well correlation between the two. In study conducted by Zukin DD et al [14] observed that the sign with highest positive predictive value for the presence of any radiographic abnormality was tachypnea, and chest examination findings such as crepitation and abnormal breath sounds. The disagreement between the diagnosis by clinical examination and radiological examinations is common. However, radiological examination appears to have greater impact on diagnosis and management when any inconsistencies arise. Also routine investigations like white blood cell count (WBCs), Differential count (DC), and erythrocyte sedimentation rate (ESR) may provide a clue in differentiating bacterial from viral pneumonia. However, their sensitivity and specificity is low. Blood culture is 


\section{Case Report}

helpful in getting best information on bacterial etiology in patients with pneumonia, despite the fact that sensitivity of this method is somewhat lower.

\section{Conclusion}

By this study it can be concluded that clinical diagnosis by WHO ARI criteria are very sensitive and can be applied to hospitalized children. Routine hematological investigations and blood culture will not give much information regarding severity or etiology of illness. Chest X-ray is valuable aid in the diagnosis of pneumonia in children. Also follow up chest roentgenogram is vital for evaluating the response in pneumonia. All authors had equal contribution in conduction of the study and manuscript writing.

Funding: Nil, Conflict of interest: None initiated, Perission from IRB: Yes

\section{References}

1. Park K. Acute respiratory infections. In: Park's text book of preventive and social medicine, 20th edi. Jabalpur: M/s Banarasidas Bhanot Publishers; 2009. P. 151-9

2. World Health Organization programme for the control of acute respiratory infections. Acute Respiratory Infections in children: Case Management in small hospital in developing countries. A manual for doctors and other senior health workers, Geneva: WHO; 2004.

3. World Health Organization programme for the control of acute respiratory infections. Technical bases for the WHO recommendations on management of pneumonia in children at first level health facilities Geneva: WHO;1995.

4. Jadavji T, Law B, Lebel MH, et al. A practical guide for the diagnosis and treatment of pediatric pneumonia. CMAJ. 1997 Mar 1;156(5):S703-11.

5. Revised WHO classification and treatment of childhood pneumonia at health facility: EVIDENCE SUMMARIES. World Health Organization. 2014. from: http://apps.who.int/iris/bitstream/ handle/10665/ 137319/9789241507813_eng.pdf?sequence $=1$

6. Reddaiah VP, Kapoor SK. Acute respiratory infections in under five: Experience at comprehensive rural health services project hospital Ballabgarh. Indian J Community Med 1995;20:1-4.

7. Sehgal V, Sethi GR, Sachdev HP, Satyanarayana L. Predictors of mortality in subjects hospitalized with acute lower respiratory tract infections. Indian Pediatr. 1997 Mar;34(3):213-9.

8. Drummond P, Clark J, Wheeler J, et al. Community acquired pneumonia--a prospective UK study. Arch Dis Child. 2000 Nov;83(5):408-12.

9. Kumar N, Singh N, Locham KK, Garg R, Sarwal D. Clinical Evaluation of acute respiratory distress and chest wheezing in infants. Indian Pediatrics 2002;39: 478-83.

10. Broor S, Pandey RM, Ghosh M, et al. Risk factors for severe acute lower respiratory tract infection in under-five children. Indian Pediatr. 2001 Dec; 38 (12): 1361-9.

11. Gupta D, Mishra S, Chaturvedi P. Fast breathing in the diagnosis of pneumonia--a reassessment. J Trop Pediatr. 1996 Aug; 42 (4):196-9. doi: 10.1093 /tropej / 42. 4.196.

12. Virkki R, Juven T, Rikalainen H, et al. Differentiation of bacterial and viral pneumonia in children. Thorax. 2002 May;57(5):438-41.

13. Heaton $\mathrm{P}$, Arthur K. The utility of chest radiography in the follow-up of pneumonia. N Z Med J. 1998 Aug $28 ; 111(1072): 315-7$.

14. Zukin DD, Hoffman JR, Cleveland RH, et al. Correlation of pulmonary signs and symptoms with chest radiographs in the pediatric age group. Ann Emerg Med. 1986 Jul;15(7):792-6.

\section{How to cite this article?}

Mehta K, Shah V, Patel A, Kalsariya D. Clinical, Bacteriological and Radiological study of severe pneumonia in age group of 2 months to 5 years. Int J Pediatr Res.2018;5(9):474-479. doi:10.17511/ijpr.2018.i09.08. 